\title{
Opportunities for enhanced lean construction management using Internet of Things standards
}

\author{
Bhargav Dave ${ }^{\mathrm{b}, *}$, Sylvain Kubler, ${ }^{\mathrm{c}, \mathrm{a}}$, Kary Främling ${ }^{\mathrm{a}}$, Lauri Koskela ${ }^{\mathrm{b}}$ \\ ${ }^{a}$ Aalto University, School of Science and Technology, P.O. Box 15500, FI-00076 Aalto, Finland \\ ${ }^{b}$ Aalto University, Department of Civil and Structural Engineering, P.O. Box 12100, FI-00076 Aalto, Finland \\ ${ }^{c}$ University of Luxembourg, Interdisciplinary Centre for Security, Reliability $\mathcal{F}$ Trust, L-2721, Luxembourg, Luxembourg
}

\begin{abstract}
Traditionally, production control on construction sites has been challenging, and still remains challenging. The ad-hoc production control methods that are usually used, most of which are informal, foster uncertainty that prevents smooth production flow. Lean construction methods such as the Last Planner System have partially tackled this problem by involving site teams into the decision making process and having them report back to the production management system. However, such systems have relatively long "lookahead" planning cycles to respond to the dynamic production requirements of construction, where daily, if not hourly control is needed. New solutions have been proposed such as VisiLean, KanBIM, etc., but again these types of construction management systems require the proximity and availability of computer devices to workers. Through this paper, the authors investigate how the communication framework underlying such construction management systems can be further improved so as to fully or partially automate various communication functions across the construction project lifecycle (e.g., to enable lean and close to real-time reporting of production control information). To this end, the present paper provides evidences of how the Internet of Things (IoT) and related standards can contribute to such an improvement. The paper then provides first insights - through various construction scenarios - into how the proposed communication framework can be beneficial for various actors and core business perspectives, from lean construction management to the management of the entire building lifecycle.
\end{abstract}

Keywords: Lean construction, BIM, Internet of Things, Standards, Supply Chain Management

\section{Introduction}

Production can be conceptualized in three complementary ways: Transformation, Flow and Value (TFV) $[1,2,3]$. In traditional production management, the flow aspect has often been neglected, and particularly the information flow that is quite important from a lean construction management perspective since it affects all other resource flows significantly $[3,4]$. In the Last Planner ${ }^{\circledR}$ process of production planning [5], the site team needs accurate resource information about the construction tasks in order to effectively conduct lookahead and weekly planning activities. In this regard, Caldas et al. [6] mention that in a fragmented and dynamic environment, the integration and exchange of information between various organisational information systems and sources is crucial for efficient production management. However, as the construction industry is a project-based

\footnotetext{
${ }^{*}$ Corresponding author

Email addresses: bhargav.dave@aalto.fi (Bhargav

Dave), sylvain.kubler@uni.lu (Sylvain Kubler),

Kary.Framling@aalto.fi (Kary Främling),

lauri.koskela@aalto.fi (Lauri Koskela)

industry, such information often lies in disparate systems that are not always available to the site team, or even interoperable with one another, which is a major hurdle to reach such efficiency $[7,8,9]$. Traditionally, the problem of disintegration has been addressed by explicit one-to-one connections between information systems with the recent trends of implementing Enterprise wide Resource Planning (ERP) systems $[10,11,12]$. ERP systems often require significant development work for each connection; in most cases they do not extend to site-based processes [13]; and being time and cost consuming such connections are seldom created. To compound this, most construction projects have to work with manual processes and traditional methods of communication such as phone calls, faxes and emails [14, 15], and even though this problem has been discussed extensively over the last two decades, the issue still remains unsolved. Arguably, there is a clear gap in the literature regarding communication frameworks that comprehensively address information flow requirements spanning across the construction project lifecycle, especially with a view to manage production related information.

Through this paper, the authors propose a commu- 
nication framework that makes it possible to leverage system-system, system-human and human-system communication to fully or partially automate various communication functions across the supply chain and construction project lifecycle. The objective of the paper is thus twofold: first, considering the initial communication framework of current construction management systems such as the VisiLean system [16], the paper investigates the main opportunities and challenges in extending this framework by integrating standardized IoT communication interfaces to "push" and "pull" the right (production) information to the right people and systems. Taking into consideration IoT technologies and standards becomes important in view of the rapid evolution and current impact that the IoT has in all sectors, including the construction sector $[17,18]$. According to a recent study of IDC (October 2014) about "Forecasting the Future of the Internet of Things in Europe", the number of the Installed Base of Connected Devices will pass from 9.1 Billion in 2013 to 28.1 Billion in 2020 representing $17.5 \%$ of CAGR (compound annual growth rate), and the corresponding Global Revenue Forecast of IoT businesses will pass from \$1.9 Trillion in 2013 to $\$ 7.1$ Trillion in 2020. The second objective is to deliver first scenarios and related benefits of using IoT standards as communication layer of VisiLean, or any similar system (e.g., KanBIM).

The paper is structured as follows: section 2 presents the research methodology and underlying hypotheses. Section 3 defines the importance of production and information management in lean construction and gives insight into the main information streams to be tracked and controlled from head office, to site office, up to the field. Section 4 investigates how VisiLean can be used based upon the adopted IoT standard by highlighting the main benefits and challenges. First proofs-of-concept of this lean construction management system (i.e., VisiLean relying on the adopted IoT standard) are presented in section 5 through several construction scenarios; discussions and conclusions follow.

\section{Research methodology and hypothesis}

It is hypothesized that the ubiquitous nature of IoT communication standards will improve the efficiency of information flow over the lifecycle of a construction project. The research is methodically aligned with the design science method [19, 20], where the process begins by selection of a real-life problem (in this study, from the construction project lifecycle). It is followed by a thorough review of the problem area, i.e. application of information management tools to manage information flow in construction management. A framework for lean production system and project lifecycle management incorporating new communications standards is then developed. Based on the proposed framework, a prototype and use case scenarios are described, providing proofs-of-concept. The further stages of the design science method (i.e., evaluation of the framework in real-life use cases) and contribution to theory are not treated within the scope of this paper, they will be covered in subsequent publications through prototypes, and further piloted construction projects.

Before beginning to discuss the production and information management from lean perspective, it is appropriate to provide a basic definition of the key concepts used throughout the paper, namely:

- Lean Construction: refers to the application and adaptation of the underlying concepts and principles of the Toyota Production System (TPS) to construction. As in TPS, the focus is on reduction in waste, increase in value to the customer, and continuous improvement;

- Last Planner System (LPS): collaborative planning and scheduling system developed by Ballard, (2000). The system provides a detailed production planning and control workflow that tackles variability and "flow" aspects in the construction management and involves the operatives in the field in the planning process;

- Lean Construction Management System: refers to any software-based construction management that supports the lean construction management workflows, and particularly LPS. Such examples can be found in VisiLean [21], KanBIM [4] and LEWIS [22] in the research arena, or still OurPlan $^{1}$ in the industry arena.

\section{Production and information management in lean construction}

In Figure 1, an overview of workflow control on construction projects from a lean perspective is given by Howell and Ballard [23] who argue that the planning function provides directions to the governing execution processes, while controls provide measurement of conformance to directives along with inputs for future planning. From this vision, two types of information flows play a crucial role in construction management, namely information flows needed to efficiently carry out long-, medium- and short-term planning tasks (flow represented by bold frames and arrows in Figure 1), and information flows needed to efficiently execute and control production in the field (flow represented by dashed frames and arrows). Accurate and timely information availability throughout

\footnotetext{
${ }^{1}$ http://our-plan.com/about-page
} 


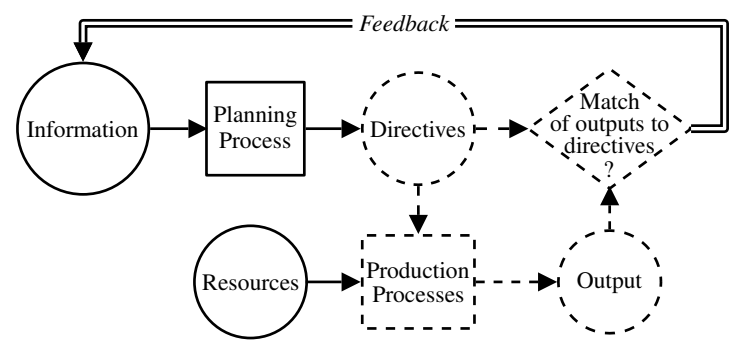

Figure 1: Relationships between planning and control [23]

the construction project, and even beyond (i.e., use and disposal phases of the facility), is a necessary condition to optimally plan and schedule the construction tasks.

Within this context, section 3.1 provides a general discussion on information flow and task management in production, their importance, and the main issues that remain to be solved. Section 3.2 focuses on existing construction management systems that aim to address such issues. On the basis of the opportunities and challenges as discussed in the literature, section 3.3 gives a concise view of the paper objective.

\subsection{Information flows for production}

Within the Last Planner System (LPS), "flows" and "tasks" have to be considered parallelly because the realization of tasks heavily depends on flows, and the progress of flows in turn is dependent on the realization of tasks [24]. One of the key functions of LPS is the "make ready" process that is part of the medium term planning (often called lookahead planning), where constraints to each task is identified (constraints refer to all those activities/inputs and resources that are required to complete a task) [24] and responsibility to remove them is assigned to task leaders (foremen, site supervisors, etc.). Researchers have discussed the importance of lookahead planning, and more particularly its role in successfully delivering construction projects (mainly due to reduced variability and improved workflow) [25, 26, 27]. It has also been argued that lookahead planning is one of the most difficult aspects to implement from the LPS [28]. One of the reasons for this is that on traditional construction projects where no software-based systems are used, there is currently no mechanism to track or anticipate the impact of identified constraints on workflow reliability before the execution week, or even until the Percent Plan Complete ${ }^{2}$ is measured [30]. Researchers have put forward proposals to tackle the constraint or resource management on

\footnotetext{
${ }^{2}$ Percent Plan Complete helps to improve the workflow and process reliability by constantly (weekly) calculating the percentage of plan reliability and making it visible and transparent across the whole team [29].
}

construction projects by providing site specific interfaces, e.g. with LEWIS [22] or KanBIM [4]. However, these systems rely on data input provided by workers in the field, and do not necessarily extend the service to external partners in the supply chain such as subcontractors or suppliers. Additionally, the tracking of constraints availability (i.e., prerequisite resources) is quite hard as the information related to their current status is not aggregated or synchronised by any function or system [3]. Confirming this point, Formoso and Isatto [31] describe the main flaws in production management as follows:

- Production management and planning is interpreted simply as preparing a Gantt chart and not much effort is made to synchronise accurate project information [32]. While there have been recent attempts to overcome this issue through frameworks such as Service Oriented Architecture $[33,34]$, or through LEWIS or KanBIM, they do not yet overcome the problem of complex and distributed information systems in construction supply chains;

- There is a general lack of formal systems dedicated to the control aspect in production management, where it usually depends on verbal exchanges between site teams and managers. Control is also dependent on short-term decisions and is seldom linked to long-term plans [35]. While some recent web based management systems and field management applications such as Our-Plan attempt to overcome these problems by providing a web based collaborative interface similar to VisiLean or KanBIM, it still relies on workers' input in the field or intervention from a site supervisor;

- Many construction companies tend to emphasise the control related to global project aims, and fulfillment of contracts, rather than production control [36]. Within this context, spotting problems in the production system and defining corrective lines of action often becomes challenging [37];

- Information \& communication technology (ICT) systems have not been very effective in production planning as they are mostly procured and implemented without identifying user and system integration requirements $[9,38]$. This leads to further instability in production management and creates waste through irrelevant and large amounts of information that do not support proactive elimination of problems but only informs about them [39];

- There is a lack of solutions to integrate, synchronize, and present production information 
Table 1: Level of functional integration in the construction industry: survey carried out in USA with 101 valid respondents [13] Level of integration

Full integration with other parties (all functions and many different entities are integrated with seamless real-time integration) 1.3

Full integration (all functions integrated with seamless real-time integration)

Partial seamless integration (several functions integrated with seamless real-time integration)

32.9

Partial relayed integration (several functions computerized and consolidated in certain periods (daily, weekly or monthly)

No integration (several standalone computer applications with no integration)

Table 2: Proposed information integration frameworks

Framework 1: Teicholz et al. [47]

1 - Horizontal integration of multiple disciplines on the project

2 - Vertical integration through the project lifecycle

3 - Longitudinal integration over time to allow knowledge capture/reuse
Framework 2: Rezgui et al. \& Zhu et al. $[10,55]$

1 - Communication between applications

2 - Knowledge based interfaces between multiple applications

3 - Integration through geometry

4 - Integration through a shared project model holding information relating to a project according to a common infrastructure model throughout the construction project, while considering all stakeholders' requirements and contexts. In most construction projects, each building stakeholder uses its own system and technologies which, coupled with the fragmented nature of construction supply chain, results in islands of information and knowledge across the whole industry [40, 41].

The problem of system fragmentation in the construction industry is well known [42, 43, 44, 45], and although mainly large sized construction firms dominate the industry, they rarely employ direct labour; instead they hire services of subcontractors and specialist firms to manage the delivery of construction projects. As construction is a project-based industry, each project brings together several SMEs (Small and Medium-sized Enterprises); in Europe, there are approximately 2.3 million companies in the construction sector that employ 11.8 million workers; $71 \%$ of these employees work in SMEs, where the average size of a company is around 5 employees [46]. Within this context, a necessary condition for a smooth functioning of production is that processes and information systems brought by all actors/SMEs must be horizontally aligned with each other [47]. However, due to the absence of long term relationships, such an alignment takes a significant amount of time and resources [48] which, in turn, affects the decision making process.

The earlier consensus amongst researchers and practitioners has been that implementing ERP systems results in a well-integrated system that reduces duplication of work and increases efficiency in general [49]. This view has led to a significant proportion of construction companies implementing some form of Construction Enterprise Information Systems (CEIS) in the last 15 years in the hope of integrating several internal and external functions such as procurement, accounting, human resources, asset management, etc. [50]. However, in a study carried out by Tatari et al.
[13] into the current state of CEIS, findings contrary to this belief are reported. The survey has shown that only $16 \%$ of participants were satisfied with their current level of integration from their CEIS implementation. Table 1 (adapted from [13]) shows that most construction companies do not realise full integration, with only $1.3 \%$ claiming full integration across the whole supply chain, and only $12.7 \%$ claiming full integration internally. Also, out of 101 firms studied, only $4 \%$ had actually implemented project management modules, leaving the actual core production processes unchanged. This reinforces the view that the majority of ICT solutions within the construction industry are applied to the peripheral processes, thus neglecting improvement of the core production processes. Seppanen et al. [51] have attempted to address the core production processes through integration of a location-based scheduling method and LPS workflow in a software system. Although location based management is of importance, the proposed systems mainly focus on the upfront scheduling processes, and less on the actual field based production processes. Also, they do not provide interfaces to synchronise or tackle resource related information.

Information integration issues in construction have been discussed quite intensively by researchers [52, $46,53,54]$ and several integration frameworks have been proposed; Teicholz [47] argued for a three dimensional framework, while Rezgui et al. [10] and later Zhu et al. [55] opted for a four dimensional one, as reported in Table 2. Following these two framework definitions, the lean construction framework developed in this paper aims to cover the three aspects comprising Framework 1 ( $c f$. Table 2) and the two first aspects of Framework 2.

\subsection{Existing lean construction management systems}

One of the most important information within the context of production planning and scheduling is that of resource flows or constraints [24]. Information 


\begin{tabular}{|c|c|c|}
\hline Task input & Information type & Hosting system \\
\hline Material & Estimating, Inventory, Procurement & $\begin{array}{l}\text { Mostly handled by ERP type applications that handle pur- } \\
\text { chase requisitions, purchase orders, supplier management }\end{array}$ \\
\hline Equipment- & Asset management, resource booking, plant hire & Possibly through ERP systems \\
\hline Manpower- & Human resource management, subcontractor's payroll & In most cases ad-hoc site based communication \\
\hline Space & $\begin{array}{l}\text { Project plans, drawings, BIM (Building Information Mod- } \\
\text { eling) models }\end{array}$ & $\begin{array}{l}\text { Currently no systems cater to the need of space management } \\
\text { for project execution }\end{array}$ \\
\hline Design & $\begin{array}{l}\text { Individual or merged design models (architectural, struc- } \\
\text { tural...), drawings, tendering, estimating, building regula- } \\
\text { tions such as local or national authorities }\end{array}$ & $\begin{array}{l}\text { BIM systems and tendering and estimation systems, project } \\
\text { extranets }\end{array}$ \\
\hline Predecessor & A production management system & $\begin{array}{l}\text { An ad-hoc verbal communication system or through the } \\
\text { LPS collaborative meetings }\end{array}$ \\
\hline $\begin{array}{l}\text { External } \\
\text { conditions }\end{array}$ & Weather forecast engines, safety management system & $\begin{array}{l}\text { These are indicative/predictive systems, but their integration } \\
\text { to the system at the task level may still be beneficial }\end{array}$ \\
\hline
\end{tabular}

regarding the status of these constraints is required throughout the task lifetime, starting from the production scheduling process (i.e., when the task is planned), to the make-ready process (i.e., when the constraints are removed), up to the execution process (i.e., when the task is executed in the field). The flow of information related to these activities strongly depends on the type of project, the supply chain configuration, as well as the type of information systems implemented in each organisation. Table 3 provides a plausible scenario of where the information could reside for individual resources. It is important to make available all these information sources to the LPS during the planning and scheduling sessions, but also to ensure that information is visual in nature, synchronised with all systems (for information consistency purposes), and easy to understand.

Dave [21] provides an information system for construction management named VisiLean (prototype system under development) that addresses all three TFV of production, where traditional systems have predominantly focused only on the Transformation (T) aspect. VisiLean also achieves the integration of the core requirements for supporting lean construction management workflow, among which the support for: i) constraint analysis and management; ii) collaboration work negotiation and communication among the project team members; iii) "push" flow control and plan stability; $i v$ ) process and product visualisation at the field level. A similar system called KanBIM was proposed in [4, 36] and, as VisiLean, it helps fulfilling the set of items listed above. However, both systems are facing the same problem when dealing with information exchange between heterogeneous information sources, and between site office-based processes and field-based processes. Other researchers have also attempted to develop lean production management systems such as LEWIS [22], Workplan [56], and Integrated Project Scheduler [57]. However, these systems do not provide field management specific interfaces, neither do they attempt to address the resource management integration. The recent commercial sys- tems such as Synchro [58], Autodesk Navisworks [59], Bentley ConstructSIM [60], Autodesk BIM360 [61], etc., attempt to synchronize project management information with BIM models. However, these systems do not provide an interface to synchronize resource information or to visualize real-time production statuses. As a result, there is a clear need for more generic communication systems that address the endto-end construction process, from head office to the site office to the field, with feedback loops between each other as depicted in Figure 2.

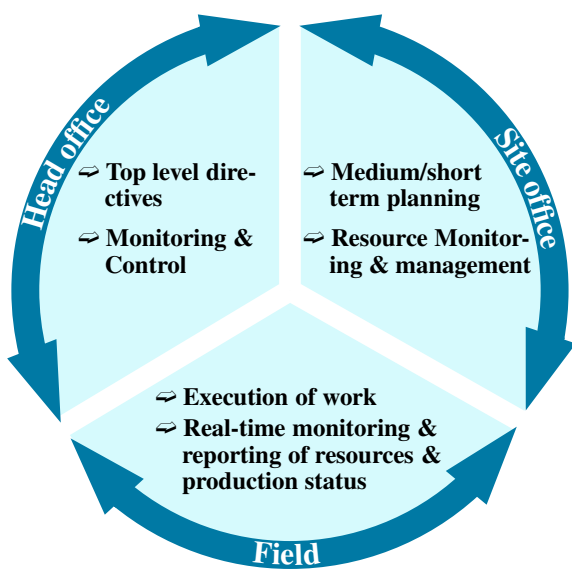

Figure 2: Communication loop between locations in a project

\subsection{Challenges in existing information systems for lean construction management}

As previously mentioned, recent construction management systems such as VisiLean or KanBIM have been developed to address the aspect of lean construction management workflow, while being integrated with the product model (BIM) in a visual way. Even if they improve collaborative production management, they still fail in avoiding system fragmentation throughout the construction project. They also fail in supporting important communication features such as the "push" and "pull"-based mechanisms that significantly impact on production control. According 
Table 4: Information categories to be "pushed" to the work teams through the construction management system Information Reason(s) to be "pushed" to the field

\begin{tabular}{|c|c|}
\hline $\begin{array}{l}\text { Medium term } \\
\text { plan }\end{array}$ & $\begin{array}{l}\text { Known as lookahead planning (part of the make-ready process in LPS), a collaborative meeting takes place between } \\
\text { all major stakeholders, where the tasks from a } 2-6 \text { week window are analysed for constraints and, if necessary, for } \\
\text { rescheduling. Task leaders have to remove the constraint before the weekly planning meeting, and any task that is not } \\
\text { ready by this time will not be selected for execution. However, as the production crew spends a majority of the time } \\
\text { in the field, it is considered important to provide them with an easy-to-use interface through which they can modify the } \\
\text { status of a constraint without having to go back to the office }\end{array}$ \\
\hline Execution plan & $\begin{array}{l}\text { It defines the activities for any given crew member for the current week. The following information for each task should } \\
\text { be made available in the field: } i \text { ) task name, ii) location iii) resources/constraints } i v \text { ) link to product model (BIM) }\end{array}$ \\
\hline $\begin{array}{l}\text { Production status } \\
\text { monitoring \& } \\
\text { control }\end{array}$ & $\begin{array}{l}\text { Workers need to be guided towards the execution of planned tasks to ensure proper control in the production system. In } \\
\text { this regard, current statuses of relevant production tasks (including notifications of predecessors being complete), changes } \\
\text { to production plans and approaching execution/constraint removal deadlines need to be communicated to workers }\end{array}$ \\
\hline $\begin{array}{l}\text { Production status } \\
\text { reporting }\end{array}$ & $\begin{array}{l}\text { Production status reporting encompasses workers communicating actions such as starting, stopping or completing a } \\
\text { task and also flagging imminent problems with ongoing tasks. Currently, workers communicate with each other in an } \\
\text { informal way and report the work/task status to their foreman in a weekly or daily meeting. However, given the dynamic } \\
\text { nature of the construction site, it would be beneficial if such information is instantaneously captured and "pushed" to the } \\
\text { construction management system }\end{array}$ \\
\hline $\begin{array}{l}\text { Automated } \\
\text { resource tracking }\end{array}$ & $\begin{array}{l}\text { With the integration of electronic procurement systems and enterprise resource management type applications in con- } \\
\text { struction industry, it is now possible to send automated messages regarding delivery of resources such as material, com- } \\
\text { ponents (e.g., precast concrete) and equipment. Moreover, with the advent of the IoT and related technologies (RFID, } \\
\text { GPS, sensors...), it is possible to track the exact location of the incoming resources }[64,65] \text {. It can therefore be en- } \\
\text { visioned that wherever possible, the production system should integrate real-time location of resources so as to provide } \\
\text { workers with up-to-date information for improved production planning and execution }\end{array}$ \\
\hline
\end{tabular}

to [62], push systems schedule the release of work, while pull systems authorise the release of work on the basis of system status. The underlying feature of the pull systems, like Kanban, is that they establish a cap for work-in-progress which, as Little's law shows, will also keep the cycle time in control. A production control system can also be a mixed push-pull system, as the system proposed by Huang and Kusiak [63] that pushes through certain manufacturing stages and pulls elsewhere based on the characteristics of these stages. The authors argue that this is superior to a push system, while avoiding some inherent problems of pull systems.

Table 4 describes the main categories of information that should be pushed to the work teams through the construction management system. Although the concept of pushing or making available the right production information, to the right person, at the right time and place, has been conceptually considered in VisiLean, it has not yet been implemented. As a result, the primary objective of this paper is to investigate how IoT technologies can be combined with VisiLean in order to concretize this conceptual view, while highlighting the main opportunities and challenges. This lean construction management system is presented in section 4 and first proofs-of-concept are given in section 5 .

\section{VisiLean based upon IoT standards}

The use of high abstraction-level communication interfaces is of the utmost importance to leverage inter- and intra-enterprise information systems. To this end, our research considers recent IoT standards published by The Open Group IoT Work Group, namely the O-MI (Open-Messaging Interface) $)^{3}$ and O-DF (Open-Data Format) ${ }^{4}$ standards [66, 67] that provide sufficiently generic interfaces to exchange any types of information between any types of systems or smart products. To obtain greater details on the benefits of those IoT standards, the reader is referred to $[68,69,70,71]$ where official standard specifications, associated history, comparison studies with other IoT standards, and concrete proofs-of-concepts are presented. To briefly summarize all of this, O-MI and ODF standards emerged out of the PROMISE EU FP6 project [72], in which real-life industrial applications required the collection and management of product instance-level information for many domains involving heavy and personal vehicles, household equipment, phone switches, etc. Information such as sensor readings, alarms, assembly, shipping events, and other information related to the entire product lifecycle needed to be exchanged between several organisations. Initially (and in previous papers), the standard names were QLM-MI and QLM-DF (QLM standing for Quantum Lifecycle Management) but were finally renamed (before the official specification publication in October 2014) O-MI and O-DF. O-MI is specified as the 'communication level' (defining what kinds of interactions between O-MI nodes are possible) and $\mathrm{O}-\mathrm{DF}$ is specified as the 'format level' (defining the structure of IoT information contained in the message). In the following, the integration of both standards (O-MI and O-DF) with VisiLean is presented, along with a discussion about how such IoT standards contribute to leverage such a traditional lean

\footnotetext{
${ }^{3}$ https://www2.opengroup.org/ogsys/catalog/C14B

${ }^{4}$ https://www2.opengroup.org/ogsys/catalog/C14A
} 


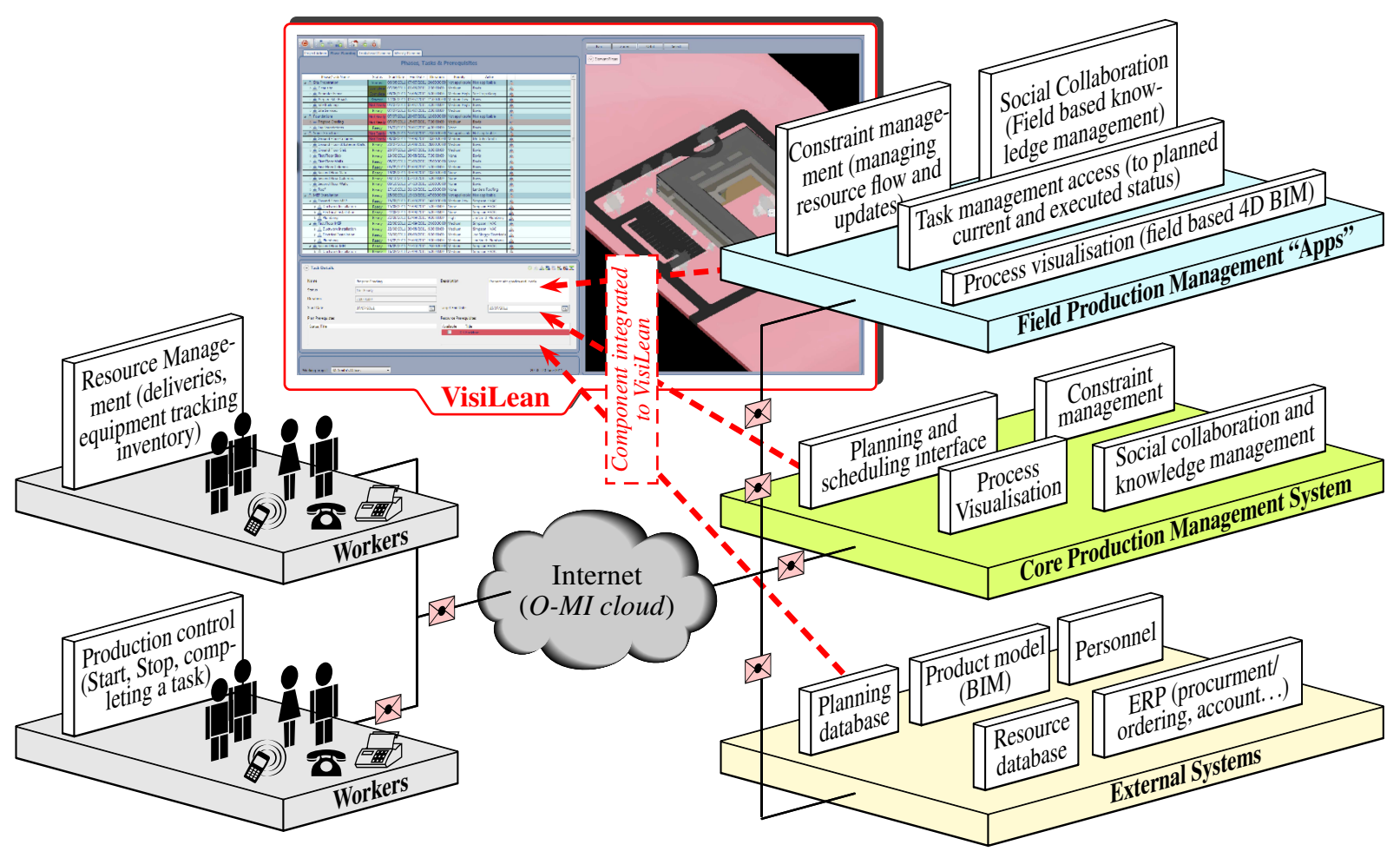

Figure 3: Schematic diagram of the enhanced lean construction management (VisiLean based upon O-MI and O-DF standards)

construction management system. First, let us note that VisiLean is built on the following components:

- Production planning and control workflow: well-established lean construction methods are used in VisiLean such as LPS (support for long-, medium- and short-term planning cycles, including constraint management);

- Process and product integration: it provides the visualization of the production planning process (LPS workflow), the BIM model, and a one-toone mapping of the task to the corresponding BIM element. Such simultaneous visualization improves planning reliability as the LPS gets access to the most complete and up-to-date information on production in a single interface during planning and execution;

- Visual controls and information in production: it supports the "pull"-based method of production by directly providing the interface for lean construction workflow in a visual way. It builds on the visual management principles such as KanBan and Andon [73]. The visual representation of tasks in the planning as well as the BIM window (using colour assignments) helps to improve the visualization of production at any given point in the project schedule.

Figure 3 gives insight into the three major components that are (or aim to be) integrated to VisiLean
[21] (see red/dashed arrows), namely: i) Field production management "Apps"; ii) Core production management system; and iii) other External systems. Figure 3 also emphasises how the adopted IoT standards (O-MI/O-DF) are used to enable communications between the VisiLean system with the iv) Resource management and $v$ ) Production control systems (see "Workers" in Figure 3).

In this regard, O-MI provides interfaces to exchange construction information between a wide range of O-MI nodes (e.g., VisiLean system, databases of distinct building stakeholders, phones, RFID systems, USB sticks...), regardless of the system or application features. In practice, O-MI/O-DF standard specifications are middleware-independent. In previous demonstrators, they have been implemented e.g. in the form of "software agents" in DIALOG middleware [68]. Three types of communications are defined in the O-MI specifications: $i$ ) Write (used for sending information updates to O-MI nodes); ii) Read (used for retrieving information from O-MI nodes). The subscription mechanism is a cornerstone of the $O-M I$ read operation, where two types of subscriptions are available:

- Subscription with callback address: the subscribed data is sent to the callback address at the requested interval. Two types of intervals can be defined: fixed time interval-based or eventbased; 
- Subscription without callback address: the data is memorized on the subscribed O-MI node as long as the subscription is valid. The memorized information can be retrieved (i.e., polled) by issuing a new O-MI read query.

The third type of communication is iii) Cancel (used to cancel subscriptions before they expire). These three types of communications, and especially the subscription mechanisms, enable maintaining the consistency of the information flow in VisiLean and other systems/O-MI nodes with respect to the real events occurring in the field and the real task progress (e.g., for tracking resource, production planning and control, or automated procurement purposes). In short, IoT standards combined with VisiLean have the potential to close the loop between the head office to the site office to the field ( $c f$. Figure 2), and to simultaneously address the TFV aspects for enhanced lean construction management. In addition, let us note that O-MI/O-DF can be applied to any kind of information, i.e. not only physical products but also to document repositories, to query for available design documents (e.g. BIM documents); subscribing to the addition/deletion/modification of documents, and much more. Indeed, O-DF provides an extension mechanism that makes possible the creation of domain-specific extensions (i.e., respecting a specific message or information format and structure). To date, the Open Group IoT Workgroup has created one such extension, called the Physical Product Extension [74], which provides specifications for managing product lifecycle-related information. Similar extensions respecting BIM standards, such as Industry foundation classes (IFCs - ISO 16739) specifications, are planned.

\section{Scenarios and opportunities to use the enhanced lean construction management system}

Scenarios in lean construction relying on the proposed framework (i.e., O-MI/O-DF as support of VisiLean) are presented in this section. This framework will further be tested through pilot implementations in industrial setting and whose results will be analyzed. Figure 4 gives insight into the considered scenario that corresponds to a construction project of a hospital. This scenario aims, on the one hand (in section 5.1), to provide a complete map of the site by emphasising how this enhanced lean construction management framework can be beneficial for various actors and core business perspectives and, on the other hand (in section 5.2), to provide scenarios at a more technical level when using O-MI/O-DF for automatic updates in VisiLean (e.g., for task management, stock control) or notifications addressed to predefined actors (e.g., suppliers, quality manager). Finally, section 5.3 discusses the opportunities resulting from the framework to extend the scenario from lean construction management to the management of the entire building lifecycle.

\subsection{Opportunities from different lean construction perspectives}

The use of O-MI/O-DF as groundwork for the communication framework opens up a whole new spectrum of features and applications, such as resource tracking, production control in the field, and automated procurement being a few. Some of the possible scenarios are detailed in the following, but further similar services and scenarios developed in the future.

Tracking resources: constraint management and analysis that directly supports the flow aspect in production management depends significantly on accurate resource tracking information. Since O-MI/ODF allow the integration of advanced tracking tools such as RFID, QR/bar codes, and GPS systems, it is possible to track resources at each stage of the construction process. Given the hospital scenario, an order for structural steel can be tracked throughout the project, e.g. to be notified when the order is placed; when the material leaves the supplier; when it enters the site; when it is stored in a particular storage area (cf. Figure 4). The production team could therefore accurately plan the tasks that depend both on the resources contained within the order and the available ressources. Within this context, O-MI/O-DF will be used, among other things, to "push" such information to the pre-assigned recipients and devices (e.g., smartphones of the site supervisor or the project manager).

Production planning and control - field operations: it might be beneficial to update production information in real-time for minimizing both the waiting time for workers (when they depend on the task completion information) and the reaction time in case work has been stopped. The proposed framework can support a fully automated system that depends on electronic means for field communication, as KanBIM does; for example, workers with smartphones can simply use the dedicated "App" to access information about planned tasks and to set task status (i.e., started, stopped, completed) when appropriate. Furthermore, the proposed framework can support a partly automated system (e.g., a magnetic board as depicted in Figure 4). Indeed, it is recognised that not all construction projects and workers therein are equipped with, or have access to such devices. This situation may be more prominent in developing countries compared to developed countries. Also, the magnetic board (or a board displaying accurate status of the task) provides a visual "at a glance" information to all the surrounding workers and supervisors, following the visual management principles of lean. In this 


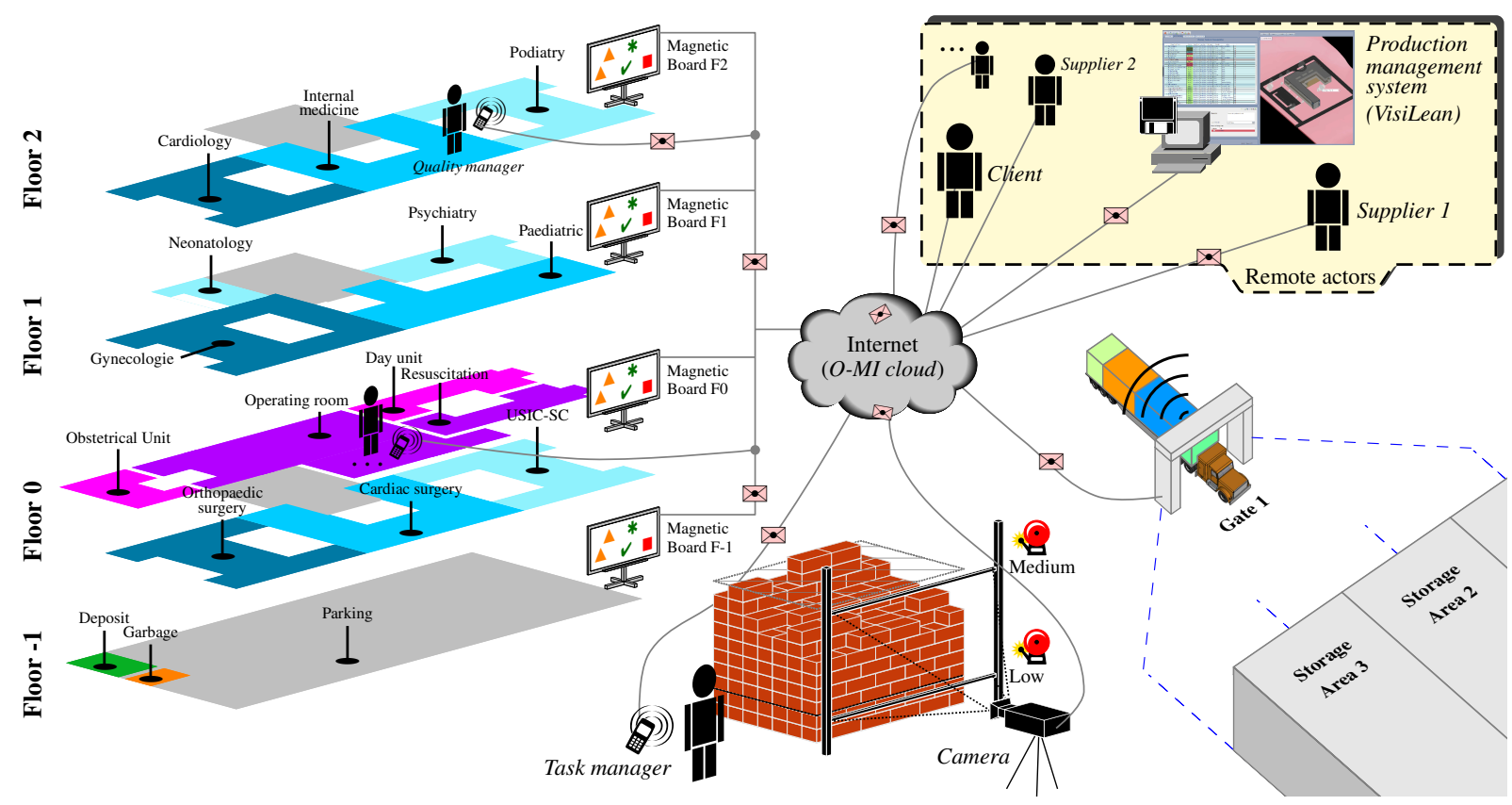

Figure 4: General view related to a construction project of an hospital involving a wide range of actors, equipments, devices, areas, etc.

regard, workers use a magnetic board and standardized symbols for setting the task status, where a fixed camera could take photos at regular intervals of time, analyse the images, and push relevant information out to relevant actors (i.e. subscribers) such as construction workers, project manager, quality manager depending on the context. Technical details about such a magnetic board scenario are given in section 5.2.

Automated procurement: procurement is an activity that is closely linked with resource flow on construction projects, and that directly impacts on productivity and ultimately project efficiency. The proposed framework aims to automate several aspects of the procurement process by providing interfaces between workers, managers and suppliers. Procurement events such as low stock notification (to suppliers or purchasing manager), shipping notification (from suppliers), storage notifications (when the material enters the site and where it is stored) can be automated. It is possible to use a similar system as the one previously described (a camera module) that takes photos of the storage area (for volume based materials such as bricks, sand...) and to send a notification to automate the ordering process when the volume falls below a predefined threshold/level ${ }^{5}$. On the other hand, the system can automate the notification process to inform workers and managers that the material needed for their tasks has been shipped, reached the site, and so on.

\footnotetext{
${ }^{5}$ An image recognition engine (using a signal processing module) is currently being developed to extract such information based on a specific infrastructure (e.g., using marked wooden stakes, etc.).
}

\subsection{Magnetic board scenario}

This scenario is presented to demonstrate that the system can support the process even when access to smart devices such as tablets and phones is not available at the worker level. A fixed camera used in combination with an image recognition engine is used to track production status and to update VisiLean. The key actors involved in this scenario are listed in Figure 5, in which the workflow/process related to the magnetic board is also depicted. The proposed workflow is used for example purposes and can obviously be adapted according to the involved actors, the project requirements and constraints, and so on:

- The process starts once the collaborative weekly planning process is concluded (see box connectors denoted by " 2 " and " 3 " in Figure 5). Note that one of the main function of the weekly planning session is to select constraint free tasks for execution for the following week ${ }^{6}$ regarding each subcontractors and task foreman;

- Following the weekly planning process, each task foreman will list their respective tasks on the magnetic board (see box connector denoted by "5"). Each task has a unique identifier noted Task_id that helps identifying the task in VisiLean. Each location on the project will have one or more magnetic boards depending on the task list; in this scenario, a magnetic board is

\footnotetext{
${ }^{6}$ At this stage, the lookahead planning meeting has already been concluded. Subsequently, the team reschedule tasks that are not ready and pick the ones that are constraint-free.
} 


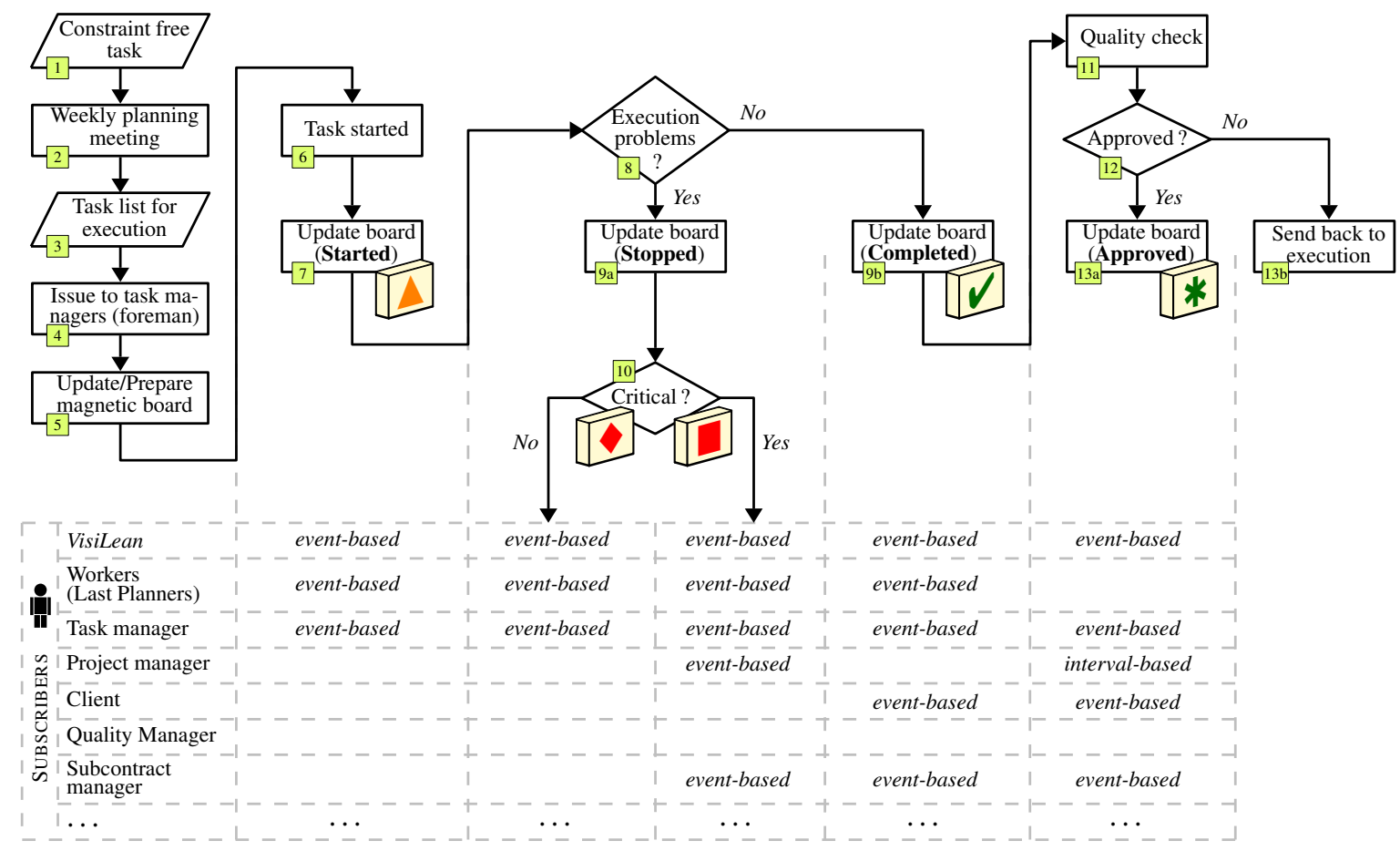

Figure 5: Magnetic board workflow detailing which actors subscribe to the different information updated on the board

available at each floor of the hospital site during the construction phase, as depicted in Figure 4;

- Once the magnetic board is setup, the project team is able to update on the board the status of each task as appropriate;

a) once the task starts, the foreman puts the triangle symbol against it to indicate "work in progress" (see box connectors denoted by "7" in Figure 5);

b) if a problem occurs (e.g., material or labour shortages, equipment breakdown), the foreman updates the task status with the "stop" symbol to mark work interruption (see box connector denoted by "10"). Such a symbol can also be used to indicate imminent problems even before they occur;

c) if there is no further problem and if the task is completed as planned, the foreman will update the status on board as "completed" (see box connector denoted by "9b");

d) Following the final Quality Check (QC) by the engineer, the task will be updated with the "QC approved" symbol (see box connectors denoted by "13a").

Various project stakeholders will likely want to receive notifications according to the task, or even according to the task status (e.g., to be notified when the task $j$ is stopped but not when it starts), as it is summarized in the table given in Figure 5 (notification either event-based or interval-based). For instance, this table shows that the task manager, as well as VisiLean want to receive the task status whatever the status ("started", "stopped", "completed", or "approved"), and immediately after the status modification. To comply with this requirement, it is necessary for both recipients to subscribe to the corresponding task by using the event-based subscription mechanism and by providing their respective address as callback. In contrast, the project manager is only interested in being notified to be notified if the task is stopped (i.e., only if it is "critical" for the project; see Figure 5) and, rather than receiving a notification each time a task is approved, the project manager is interested in receiving a weekly statement (i.e., before the weekly change of the board tasks). To this end, the project manager has to subscribe to all tasks on the board using the interval-based subscription mechanism, by setting the interval to one week, and by providing its own address as callback.

Figure 6 gives insight into how a building stakeholder is able to discover the different information available during the construction project (for read, write, subscription purposes). In this figure, the project manager uses the RESTful O-MI "discovery" mechanism [71] to discover and retrieve the exact information types (referred to as "InfoItem(s)" in the standard specifications), the objective for the project manager being to access information from the magnetic board located at Floor 1. In practice, the Unix 


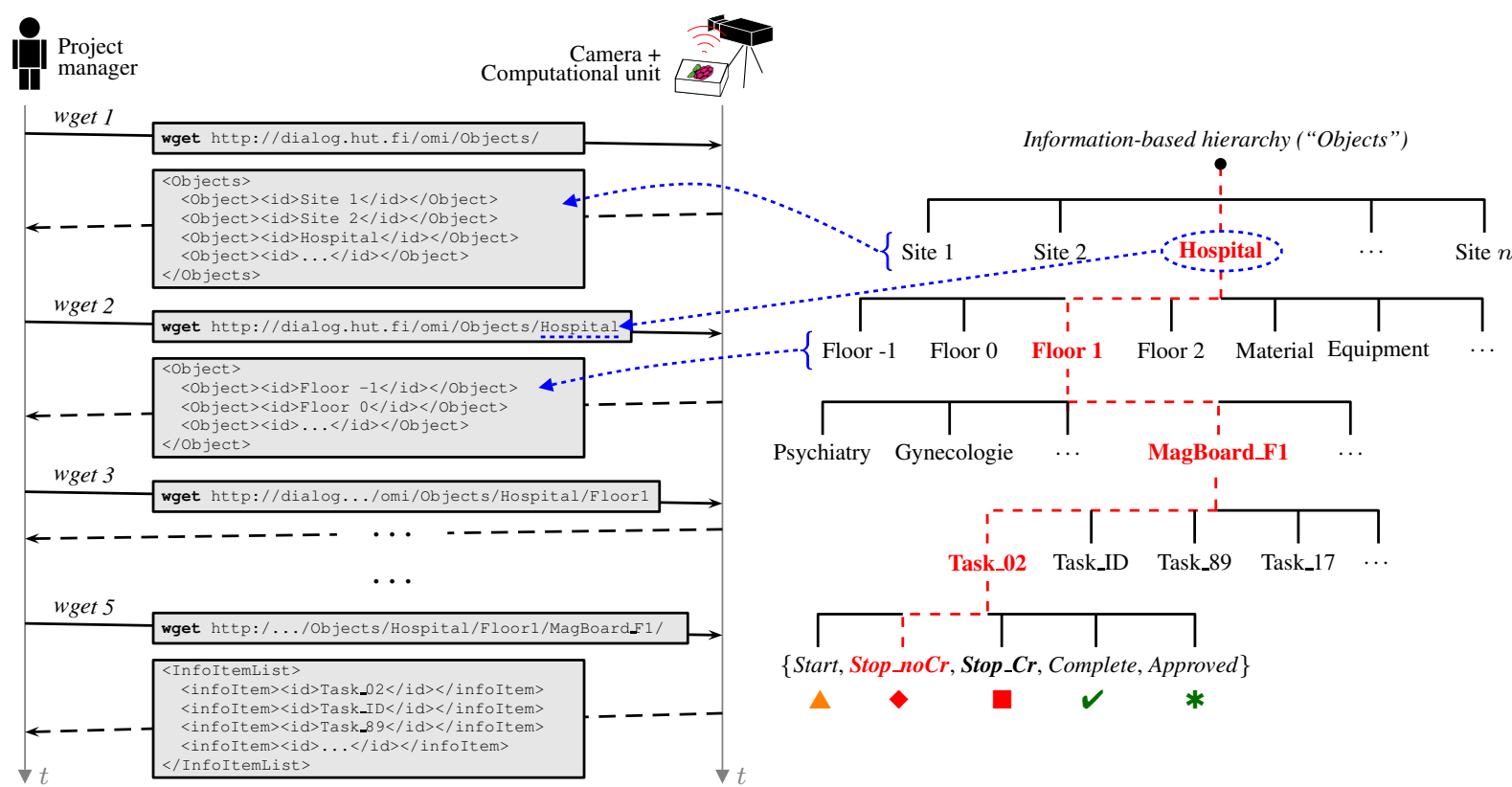

Figure 6: O-MI discovery mechanism used to discover what types of information can be accessed (read, subscribed, written) during the project

wget utility is used as shown through wget_1 in Figure 6, which returns the first level of information available in the system, namely the different sites under construction (see the response message as well as the information hierarchy). Indeed, O-DF uses a simple ontology specified using XML Schema, which is structured as a hierarchy with an "Objects" element as its top element (see Figure 6), which can contain any number of "Object" sub-elements that, in turn, can contain any number of "Object" as well "InfoItem" sub-elements (an InfoItem represents a characteristic of the Object that can be read/written, e.g. a temperature, a contact sensor, a task status, a document). Based on the response resulting from wget_1 (see Figure 6), the project manager carries on discovering the sub-elements composing the sub-levels of the hierarchy using wget_2, which returns in this scenario the different construction locations related to the Hospital site (i.e., Floor 0, Floor 1) and other information types that have been initially defined at this hierarchy level (e.g., "Equipment", "Material" classes as shown in Figure 6). It is important to note that the initial O-DF hierarchy can be defined based on standards (e.g., respecting the IFC classes), on data models dedicated to particular applications, etc.; in other words, it can be tuned according to the user and project needs. Using iterative wget (s) (see wget_2 to wget_5 in Figure 6), the project manager is able to refine his/her research to identify relevant information to his/her business activity (e.g., related to Task_02 as depicted with the dashed path through the hierarchy in Figure 6). Once appropriate Objects and InfoItems are identified, the project manager has to use the appropriate O-MI interface (write, read, subscriptions...) by setting the appropriate parameters such as the interval parameter, name of the InfoItem to be read/written/subscribed, duration of the subscription, and so on (see $[68,71]$ for examples of such queries).

Figure 7 presents the subsequent stages, i.e. after each actor subscribed to appropriate information on the board. Technically, a camera connected to a computational unit (e.g., a Raspberry PI as depicted in Figure 7) takes a picture of the magnetic board every $10 \mathrm{~min}$ and automatically interprets the status changes. In this example, two changes occurred during the last $10 \mathrm{~min}$ as emphasised in Figure 7 (related to Task_02 and Task_27). Since both statuses relate to the starting and stopping (no critical) of tasks, only the VisiLean system and Task manager receive a notification because they beforehand subscribed to this task information (see table given in Figure 5). This notification corresponds to the O-MI/O-DF response given in Figure 7, which respects the hierarchy initially established ( $c f$. Figure 6) and that includes $i$ ) the subscription ID (see row 3 of the XML message), as well as ii) the new statuses of these two tasks (see rows 9 to 13 and 14 to 18 ).

As previously stated, other similar examples and scenarios in construction projects could be imagined and developed in the future, considering the many facets of a construction project.

\subsection{From lean construction management to building lifecycle management}

The management of the entire building lifecycle, also known as building lifecycle management (BLM) is becoming an important aspect of the modern building industry due to, among other things, the complex- 


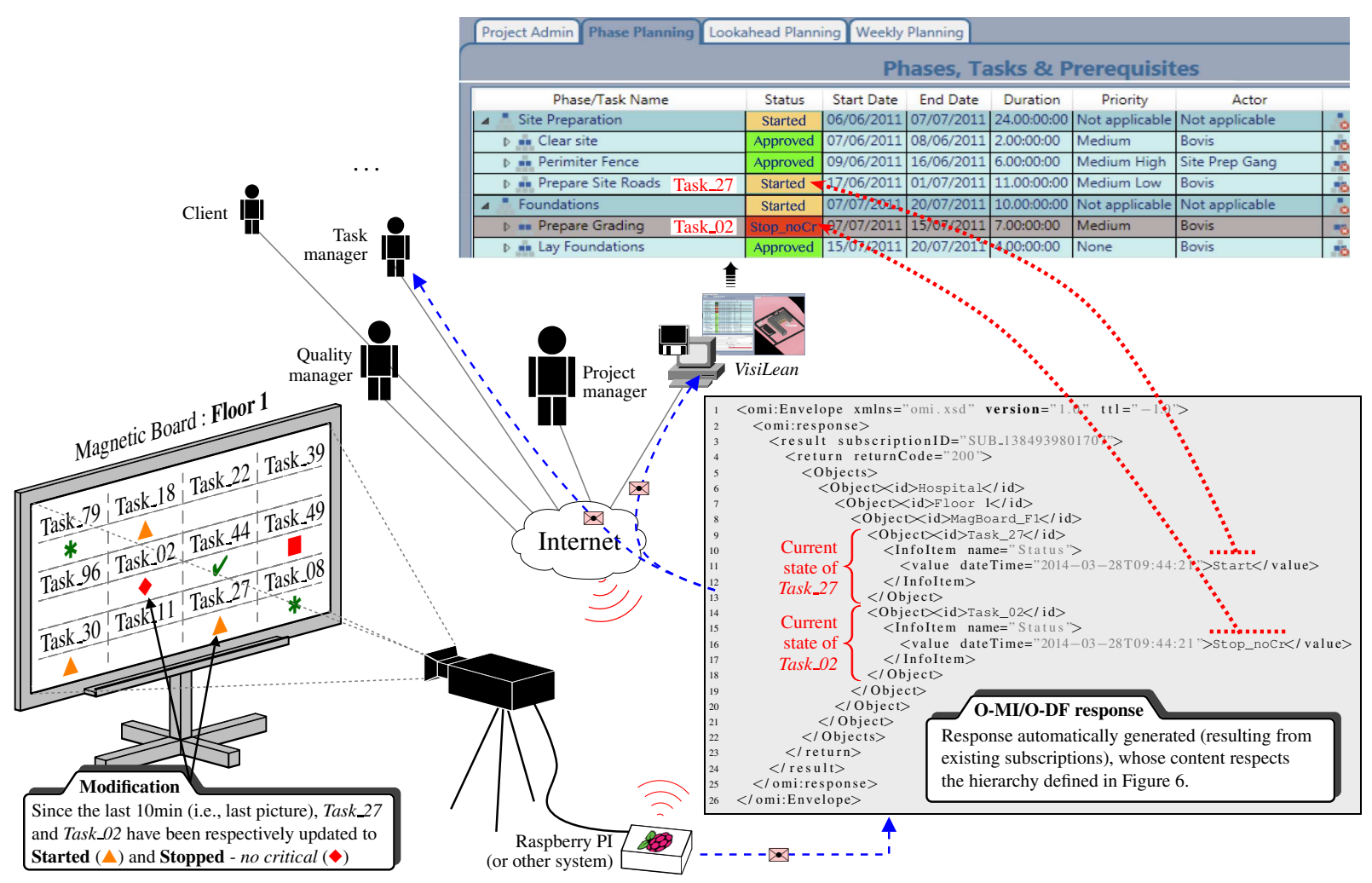

Figure 7: Magnetic board jointly used with O-MI/O-DF for tacking the production status and notifying recipients (e.g., VisiLean, managers...)

ity of a building lifecycle [75]. Indeed, within such an environment, numerous applications, processes, and data must be covered by BLM, from beginning of life (BoL) including design, analysis, production, and construction of the building, through middle of life (MoL) including its use and maintenance, up to end of life (EoL) including its recycling and disposal [75, 76, 77].

In this paper, the focus was given to lean construction management, and particularly to the VisiLean software, which focuses on BoL activities and processes as illustrated in Figure 8. However, with the use of O-MI/O-DF standards, new opportunities for enriching the basic services supported by this software could be investigated since the communication framework is able to both collect and convey realtime as well as historical data throughout the building lifetime and across organizations (see Figure 8), thus providing a way to close the information loop between various systems, actors and phases comprising the building lifecycle. The term "closing the information loop" has been chosen in this context because it is in accordance with the definition given by the research consortium working on the $\mathrm{CL}_{2} \mathrm{M}$ paradigm ${ }^{7}$ (Closed-Loop Lifecycle Management) [78, 79], which is a cornerstone for developing more advanced, complete, and customized building services. For instance,

\footnotetext{
${ }^{7} \mathrm{http}: / / \mathrm{cl} 2 \mathrm{~m} . \mathrm{com}$
}

designers (in BoL) could be provided with real-time data about the conditions of use of their buildings (i.e., information from MoL) and of retirement (i.e., information from EoL); recyclers could be provided with accurate data about the routine maintenance carried out on the building (i.e., information from MoL: e.g. to be aware about cracks or any other sign related to the building structure or appliances used inside the building), or even about modifications performed during the construction project (i.e., information from BoL). At a more concrete level, repairers or recyclers could potentially retrieve accurate information related to the construction project by requesting it from VisiLean system or any other system/database, and vice-versa. Some recent initiatives such as the Dasher project [80] underline the interest to reuse the knowledge capitalized from the design phase during the operation phase by linking existing BIM models to the different intelligent building systems. The resulting tool could therefore be used as a supervision system or as a predictive tool to predict the building evolution, or be used to obtain information related to the building structure (i.e., information from the design phase) that would help improving building's energy efficiency and health. IoT standards such as O-MI/O-DF provide such an opportunity to create a "bridge" between different actors/systems throughout the building lifetime. Figure 8 relates some benefits for each building stakeholder to access complete and 


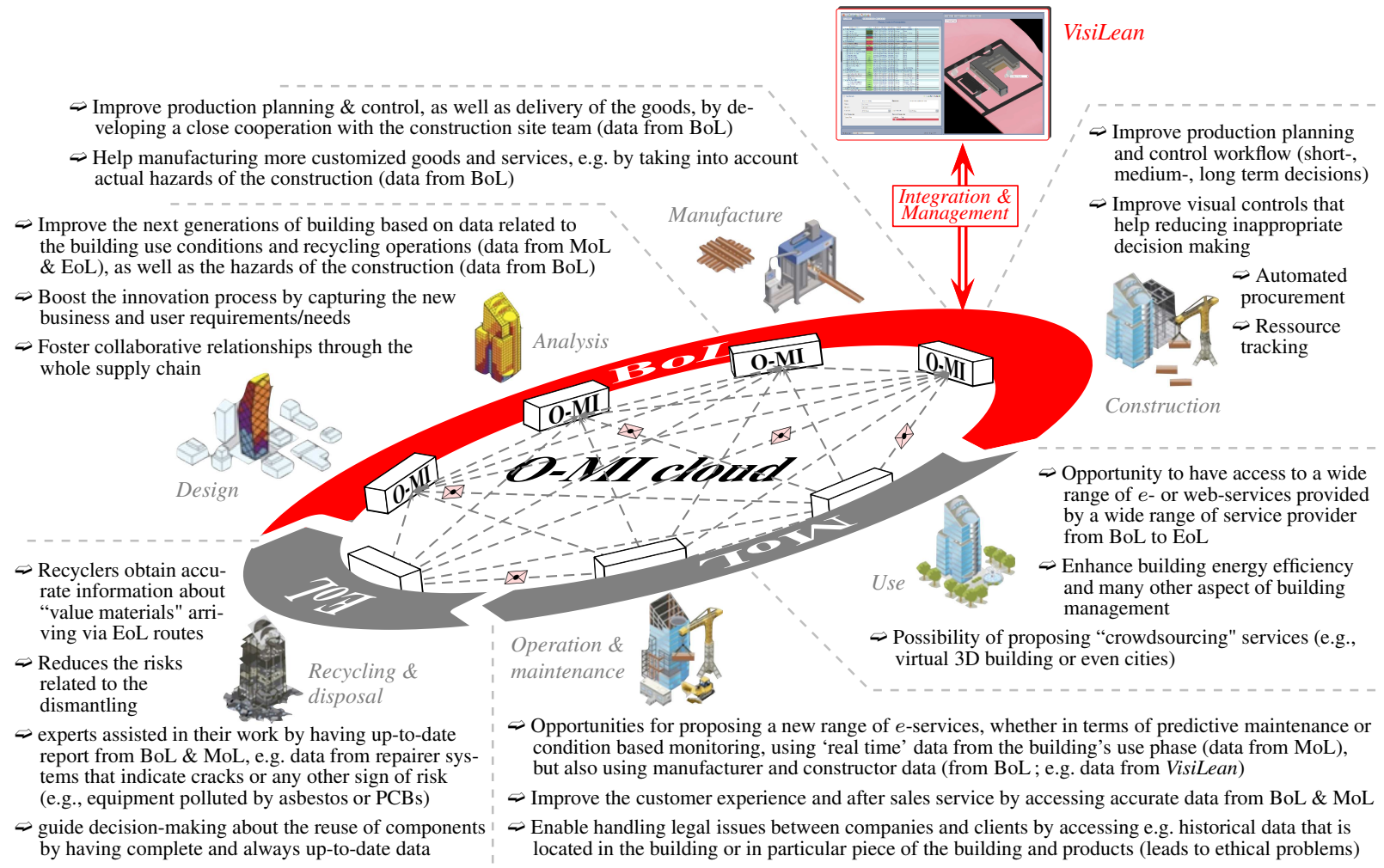

Figure 8: Typical features and benefits of the proposed framework considering the whole building lifecycle: from BoL, to MoL, up to EoL

always up-to-date data from one lifecycle phase to another.

\section{Discussion and future research}

Addressing the information flow on a construction site is a complex issue that depends on a variety of factors. A smooth information flow is essential to ensure efficient production management and control. The enhanced lean construction management system proposed in this paper takes into account the dynamic nature of construction projects, and aims to improve information flow across the lifecycle of a construction project, while being scalable. First, VisiLean addresses all the three aspects of the TFV theory by providing a platform that helps integrating, synchronizing and visualizing both product and process information simultaneously. VisiLean has been designed for use by workers in the field, and supports the Last Planner workflow by providing specific production scheduling and control features, constraint analysis and collaborative visualisation of information. It extends this workflow by providing real-time task updates and direct integration with BIM [21]. Through this work, the VisiLean application is conceptually extended to the whole project/building lifecycle, enabling realization of lean principles from design, construction, handover, and the later phases (use, maintenance and disposal). Second, the underlying communication frame- work (i.e., relying on O-MI/O-DF) has already been set up on two University campuses: in France (ENSTIB campus) [81] and in Finland (Otaniemi3D campus) ${ }^{8}$ for energy management purposes. Some of the additional opportunities as anticipated by the authors (beyond those reported in the scenarios from section 5) are:

- Integration with BIM: BIM can play a central role in both information delivery and consumption of the communication framework introduced in this paper. With its data-rich models, BIM provides both product and process related information across the whole building lifecycle, while its visual nature makes it an ideal platform for information deliveries to workers at all stages;

- Modularity: The proposed communication framework is modular and independent in nature, i.e. it is not dependent on existing systems (not even on VisiLean) for integration and can overcome challenges such as system fragmentation, system security and mobility. It supports a diverse range of communication needs (e.g., Human-Human, Human-System, SystemSystem);

- Supporting the entire lifecycle: the same communication infrastructure can serve a project

\footnotetext{
${ }^{8}$ https://dl.dropboxusercontent.com/u/61043462/dist/index.html\#/home
} 
from design to construction and delivery to handover and maintenance. As outlined in the scenarios from section 5, applications in construction can be range from logistics (tracking) to production control and commissioning, and handover. However, the same system can be extended to post-construction stages, for intelligent monitoring of assets or energy optimization purposes. This aspect makes it attractive to organisations investing in a new platform.

However, like any new solution, it is anticipated that a number of challenges will need to be overcome before this solution can be successfully implemented. Some of these challenges are:

- Integration with other systems: the suggested communication platform is not of a stand-alone nature, i.e. it relies on existing information systems to extract information from and inject information to it. The agreement on standards such as O-MI and O-DF in the IoT, or still IFC in the construction area, should play a key role in reducing development costs and times e.g. for API integrators and maintainers. However, standards will not solve all integration issues [82], there will still be a need for complementary tools such as API mediators (e.g., semantic mediators) [83] to enable the translation of existing APIs ans systems into standardised and interoperable IoT services;

- Consumption of information: further from the point raised above, even when the overall communication platform has been successfully implemented, the information should be presented to workers in a manner that is timely and effective (i.e., easy to consume);

- Information overload: with such a communication platform, it becomes easy to burden the workers with too much or irrelevant information. Hence, information delivery should be carefully thought, filtered and set up by the production team;

- Technical challenges: more powerful communication systems (access to Internet and wireless terminals) should be made available to workers and other stakeholders, and although this is now becoming quite commonplace on construction projects, it may still be an issue on some remote construction sites;

- Training and motivation: involvement of workers is essential in such a system, as still in many situations the system relies on workers for input of information, and to perform needed actions.
In this regard, user training and awareness in using advanced ICT tools remains an issue, and personalized programs adapted to each group of users/workers still need to be developed [9].

\section{Conclusion}

Managing information flow within production management is one of the critical aspects that affect the efficiency of the whole construction project, and even of the whole building lifecycle. Even after a decade of experience in developing ERP and similar systems for addressing interoperability issues, most organisations are not satisfied with their current level of data and system integration. This can be partly explained by the fact that companies do not implement solutions that provide sufficiently generic communication interfaces, rather they use communication infrastructures and applications that are often 'siloed' (i.e., designed to be domain- or vendor-specific). Without an appropriate communication framework as foundation of a construction management system, such issues will remain unsolved and organisations will not be able to evolve to meet new business needs.

Given this observation, this paper provides insight into how emerging lean construction management systems such as VisiLean or KanBIM can be enhanced by using IoT standards in order to report real-time task status from the field, while improving interoperability between all major information systems and organizations throughout the construction project. The recent IoT standards named O-MI/O-DF are considered, which provide high-level abstraction interfaces for exchanging any types of information (building information, production information, alarms, and much more) between any types of systems, smart entities/products, and people. Such standardized IoT interfaces, and particularly the O-MI subscription mechanism and its variants (with or without callback address, interval or event-based), are a great opportunity of maintaining the information flow consistency in lean construction management systems (i.e., VisiLean in this research) with respect to the real events occurring in the field and the real task progress (e.g., for tracking resource, production planning and control, or automated procurement purposes). For instance, they contribute strongly to "push" and "pull" the right (production) information to the right people and systems, thus closing the loop between the head office to the site office to the field. Different scenarios in construction are presented in this paper to help understanding $i$ ) the real opportunities and challenges of using such an enhanced lean construction management system throughout the construction phase, and even beyond (i.e., considering the operational and recycling phases of the building lifecycle); ii) the different levels of detail of the enhanced lean construction man- 
agement system (i.e., the integration of O-MI/O-DF with VisiLean), along with the first proofs-of-concept.

Both VisiLean [21] and O-MI/O-DF [68, 69] pilots have been developed, tested and validated by separate studies in the past. This research attempts to provide a framework that would lead to the interfacing of both solutions. Work is under way in developing such an interfacing (see e.g. the otaniemi3D campus in section 6), together with construction industries, so that the different use case scenarios presented in this paper can be tested and validated. In terms of future research and as was discussed in section 6 , one of the key goals is to address the whole lifecycle of a construction project, with a particular focus on taking into consideration BoL information in the use and disposal phases of a building (i.e., MoL and EoL), which will result in innovative or more advanced services, as the ones listed in Figure 8.

\section{References}

[1] L. Koskela, An exploration towards a production theory and its application to construction, Tech. rep., VTT Technical Research Centre of Finland (2000).

[2] E. Tribelsky, R. Sacks, The relationship between information flow and project success in multi-disciplinary civil engineering design, in: 18th Annual Conference of the International Group for Lean Construction, 2010.

[3] B. Dave, S. C. Boddy, L. J. Koskela, Improving information flow within the production management system with web services, in: 18th Annual Conference of the International Group for Lean Construction, 2010, pp. 445-455.

[4] R. Sacks, M. Radosavljevic, R. Barak, Requirements for building information modeling based lean production management systems for construction, Automation in Construction 19 (5) (2010) 641-655.

[5] H. G. Ballard, The last planner system of production control, Ph.D. thesis, University of Birmingham (2000).

[6] C. H. Caldas, L. Soibelman, L. Gasser, Methodology for the integration of project documents in model-based information systems, Journal of Computing in Civil Engineering 19 (1) (2005) 25-33.

[7] T. Perumal, M. N. Sulaiman, C. Y. Leong, Eca-based interoperability framework for intelligent building, Automation in Construction 31 (2013) 274-280.

[8] T. Perumal, A. R. Ramli, C. Y. Leong, K. Samsudin, S. Mansor, Middleware for heterogeneous subsystems interoperability in intelligent buildings, Automation in Construction 19 (2) (2010) 160-168.

[9] M. Hannus, A. S. Kazi, A. Zarli, Ict supported energy efficiency in construction strategic research roadmap and implementation recommendations, Tech. rep., REEB report (2010).

[10] Y. Rezgui, A. Brown, G. Cooper, J. Yip, P. Brandon, J. Kirkham, An information management model for concurrent construction engineering, Automation in Construction 5 (4) (1996) 343-355.

[11] C. H. Caldas, L. Soibelman, Automated classification methods: Supporting the implementation of pull techniques for information flow management, in: 10th Annual Conference of the International Group for Lean Construction, 2002.

[12] T. M. Froese, The impact of emerging information technology on project management for construction, Automation in Construction 19 (5) (2010) 531-538.

[13] O. Tatari, D. Castro-Lacouture, M. J. Skibniewski, Current state of construction enterprise information systems: sur- vey research, Construction Innovation: Information, Process, Management 7 (4) (2007) 310-319.

[14] D. Zhai, P. Goodrum, C. Haas, C. Caldas, Relationship between the automation and integration of construction information systems and productivity, ASCE Journal of Construction Engineering and Management 135 (8) (2009) 746-753.

[15] L. Klein, N. Li, B. Becerik-Gerber, Imaged-based verification of as-built documentation of operational buildings, Automation in Construction 21 (2012) 161-171.

[16] B. Dave, S. Boddy, L. Koskela, Visilean: Designing a production management system with lean and bim, in: Proceedings of the 19th conference of the International Group for Lean Construction, 2011

[17] Lu, W. and Huang, G. Q. and Li, H., Scenarios for applying RFID technology in construction project management, Automation in Construction 20(2) (2011) 101-106.

[18] Shou, W. and Wang, J. and Wang, X. and Chong, H. Y., A Comparative Review of Building Information Modelling Implementation in Building and Infrastructure Industries, Archives of Computational Methods in Engineering 22 (2) (2015) 291-308.

[19] E. Kasanen, K. Lukka, The constructive approach in management accounting research, Journal of management accounting research 5 (1993) 243-264.

[20] A. Hevner, S. March, J. Park, S. Ram, Design science in information systems research, MIS quarterly 28(1) (2004) 75-105.

[21] B. A. Dave, Developing a construction management system based on lean construction and building information modelling, Ph.D. thesis, University of Salford (2013).

[22] E. Sriprasert, N. N. Dawood, Multi-constraint information management and visualisation for collaborative planning and control in construction, Electronic Journal of Information Technology in Construction 8 (2003) 341-366.

[23] G. Howell, G. Ballard, Can project controls do its job?, in: 4th Annual Conference of the International Group for Lean Construction, 1996.

[24] L. J. Koskela, Management of production in construction: a theoretical view, in: 7th Annual Conference of the International Group for Lean Construction, Berkeley, California, USA, 1999, pp. 241-252.

[25] S. L. Kemmer, L. F. Heineck, M. de V. Novaes, A. M. A. Mourão, T. da C. Alves, Medium-term planning: contributions based on field application, in: 15th Annual Conference of the International Group for Lean Construction, East Lansing, Michigan, USA, 2007, pp. 509-518.

[26] F. R. Hamzeh, G. Ballard, I. D. Tommelein, Improving construction work flow - The connective role of look ahead planning, in: 16th Annual Conference of the International Group for Lean Construction, Manchester, UK, 2008, pp. 635-646.

[27] F. R., Hamzeh, I. Saab, I. D. Tommelein, G. Ballard, Understanding the role of "tasks anticipated" in lookahead planning through simulation. Automation in Construction 49 (2015) pp. 18-26.

[28] R. C. Bortolazza, C. T. Formoso, Management of production in construction: a theoretical view, in: 14th Annual Conference of the International Group for Lean Construction, Santiago, Chile, 2006, pp. 625-635.

[29] G. Ballard, Improving work flow reliability, in: 7th Annual Conference of the International Group for Lean Construction, 1999, pp. 275-286.

[30] T. S. Abdelhamid, J. G. Everett, Physical demands of construction work: A source of workflow unreliability, in: 10th Annual Conference of the International Group for Lean Construction, 2002.

[31] C. T. Formoso, E. L. Isatto, Production planning and control and the coordination of project supply chains, Construction Supply Chain Management-HANDBOOK (2008) 181-193.

[32] A. Laufer, T. R. L., Is construction project planning really doing its job? a critical examination of focus, role and process, Construction Management and Economics 5 (3) (1987) 243266. 
[33] J. C. Cheng, K. H. Law, H. Bjornsson, A. Jones, R. Sriram, A service oriented framework for construction supply chain integration, Automation in Construction 19(2) (2010) 245260.

[34] Y. Rezgui, S. Boddy, M. Wetherill, G. Cooper, Past, present and future of information and knowledge sharing in the construction industry: Towards semantic service-based econstruction?, Computer-Aided Design 43(5) (2011) 502515.

[35] C. T. Formoso, A knowledge based framework for planning house building projects, Ph.D. thesis, A knowledge based framework for planning house building projects (1991).

[36] U. Gurevich, R. Sacks, Examination of the effects of a KanBIM production control system on subcontractors' task selections in interior works, Automation in Construction 37 (2014) 81-87.

[37] G. Ballard, G. Howell, Shielding production: essential step in production control, Journal of construction Engineering and Management 124 (1) (1998) 11-17.

[38] R. A. Stewart, S. Mohamed, Evaluating web-based project information management in construction: capturing the longterm value creation process, Automation in Construction 13 (4) (2004) 469-479.

[39] V. Sanvido, B. Paulson, Site-level construction information system, journal of construction engineering and management, ASCE 118 (4) (1992) 701-715.

[40] M. Alshawi, B. Ingirige, Web-enabled project management: an emerging paradigm in construction, Automation in Construction 12 (4) (2003) 349-364.

[41] G. E. Aguilar, K. N. Hewage, It based system for construction safety management and monitoring: C-rtics ${ }^{2}$, Automation in Construction 35 (2013) 217-228.

[42] S. C. W. Kong, H. Li, Y. Liang, T. Hung, C. Anumba, Web services enhanced interoperable construction products catalogue, Automation in Construction 14 (3) (2005) 343-352.

[43] N. Bakis, G. Aouad, M. Kagioglou, Towards distributed product data sharing environments-progress so far and future challenges, Automation in Construction 16 (5) (2007) 586-595.

[44] B. Dave, L. Koskela, Collaborative knowledge managementa construction case study, Automation in Construction 18 (7) (2009) 894-902.

[45] S. Groak, The idea of building: thought and action in the design and production of buildings, Taylor \& Francis, 2013.

[46] R. Jardim-Goncalves, A. Grilo, Soa4bim: putting the building and construction industry in the single european information space, Automation in Construction 19 (4) (2010) 388-397.

[47] P. Teicholz, Vision of future practice, in: Berkeley-Stanford Workshop on Defining a Research Agenda for AEC Process/Product Development, 1999.

[48] R. Jardim-Goncalves, A. Grilo, C. Agostinho, F. Lampathaki, Y. Charalabidis, Systematisation of interoperability body of knowledge: the foundation for enterprise interoperability as a science, Enterprise Information Systems 7 (1) (2013) 7-32.

[49] M. Bergström, L. Stehn, Matching industrialised timber frame housing needs and enterprise resource planning: A change process, International Journal of Production Economics 97 (2) (2005) 172-184.

[50] K. C. Desouza, Agile Information Systems: Conceptualization, Construction, and Management, Routledge, 2007.

[51] O. Seppänen, G. Ballard, S. Pesonen, The combination of last planner system and location-based management system, Lean Construction Journal 6(1) (2010), 43-54.

[52] A. Farquhar, R. Fikes, W. Pratt, J. Rice, Collaborative ontology construction for information integration, Tech. rep., Technical Report KSL-95-63, Stanford University Knowledge Systems Laboratory (1995).

[53] I. Wu, S.-H. Hsieh, A framework for facilitating multidimensional information integration, management and visualization in engineering projects, Automation in Construction 23 (2012) 71-86.

[54] E. Viljamaa, I. Peltomaa, Intensified construction process control using information integration, Automation in Construction 39 (2014) 126-133.

[55] Y. Zhu, R. R. A. Issa, R. F. Cox, Web-based construction document processing via malleable frame, Journal of computing in civil engineering 15 (3) (2001) 157-169.

[56] H. J. Choo, I. D. Tommelein, G. Ballard, T. R. Zabelle, WorkPlan: Constraint-based database for work package scheduling, Journal of Construction Engineering and Management 125(3) (1999) 151-160.

[57] D. K. H. Chua, T. Q. Nguyen, K. W. Yeoh, Automated construction sequencing and scheduling from functional requirements, Automation in Construction 35 (2013) 79-88.

[58] www.synchroltd.com

[59] http://www.autodesk.com/products/navisworks/overview

[60] http://www.bentley.com/en-US/Products/ConstructSim/

[61] http://www.autodesk.com/products/bim-360-field/overview

[62] M. L. Spearman, W. J. Hopp, Factory Physics: Foundations of Manufacturing Management, Irwin, Chicago, IL, 1996.

[63] C. C. Huang, A. Kusiak, Manufacturing control with a pushpull approach, International Journal of Production Research 36 (1) (1998) 251-276.

[64] G. Meyer, K. Främling, J. Holmström, Intelligent products: A survey, Computers in Industry 60 (3) (2009) 137-148.

[65] D. McFarlane, V. Giannikas, A. C. Y. Wong, M. Harrison, Product intelligence in industrial control: Theory and practice, Annual Reviews in Control 37 (1) (2013) 69-88.

[66] The Open Group. Open Data Format (O-DF), an Open Group Internet of Things (IoT) Standard. October 2014. Available at www.opengroup.org/bookstore/catalog/c14a.htm. US ISBN 1-937218-59-1.

[67] The Open Group. Open Messaging Interface (O-MI), an Open Group Internet of Things (IoT) Standard. October 2014. Available at www.opengroup.org/bookstore/catalog/c14b.htm. US ISBN 1-937218-60-7.

[68] K. Främling, S. Kubler, A. Buda, Universal messaging standards for the IoT from a lifecycle management perspective, IEEE Internet of Things Journal 1(4) (2014) 319-327.

[69] S. Kubler, K. Främling, A. Buda, A standardized approach to deal with firewall and mobility policies in the IoT, Pervasive and Mobile Computing, (In Press, Corrected Proof) 10.1016/j.pmcj.2014.09.005.

[70] S. Kubler, K. Främling, Derigent, W., P2P Data synchronization for product lifecycle management, Computers in Industry 66(0) (2015) 82-98.

[71] S. Kubler, M. Madhikermi, K. Främling, QLM messaging standards: introduction and comparison with existing messaging protocols, in: Springer (Ed.), Service Orientation in Holonic and Multi-Agent Manufacturing and Robotics, Springer International, Vol. 544, 2014, pp. 237-256.

[72] D. Kiritsis, A. Bufardi, P. Xirouchakis, Research issues on Product Lifecycle Management and information tracking using smart embedded systems, Advanced Engineering Informatics 17 (3) (2003) 189-202.

[73] B. A. Tezel, Visual management: An exploration of the concept and its implementation in construction, Ph.D. thesis, University of Salford (2011).

[74] S. Parrotta, J. Cassina, S. Terzi, M. Taisch, D. Potter, K. Främling, Proposal of an interoperability standard supporting PLM and knowledge sharing, in: Advances in Production Management Systems. Sustainable Production and Service Supply Chains, Springer, 2013, pp. 286-293.

[75] I. Visa, M. D. Moldovan, M. Comsit, A. Duta, Improving the renewable energy mix in a building toward the nearly zero energy status, Energy and Buildings 68 (2014) 72-78.

[76] M. Richards, Building information management: A standard framework and guide to BS 1192, BSI Standards, 2010.

[77] G. Lee, R. Sacks, C. M. Eastman, Specifying parametric building object behavior (bob) for a building information modeling system, Automation in Construction 15 (6) (2006) 758-776. 
[78] D. Kiritsis, Closed-loop PLM for intelligent products in the era of the Internet of Things, Computer-Aided Design 43 (5) (2011) 479-501.

[79] K. Främling, J. Holmström, J. Loukkola, J. Nyman, A. Kaustell, Sustainable PLM through intelligent products, Engineering Applications of Artificial Intelligence 26 (2) (2013) 789-799.

[80] Autodesk research, Project dasher (part of the building performance project): http://www.autodeskresearch.com/projects/dasher

[81] S. Kubler, M. Madhikermi, A. Buda, K. Främling, W. Derigent, A. Thomas, Towards data exchange interoperability in building lifecycle management, in: 19th IEEE International conference on Emerging Technologies and Factory Automation, 2014.

[82] T. Espinha, A. Zaidman, H.-G. Gross, Web API growing pains: Loosely coupled yet strongly tied, Journal of Systems and Software 100 (2015) 27-43.

[83] K. Hribernik, C. Hans, C. Kramer, K.-D. Thoben, A serviceoriented, semantic approach to data integration for an Internet of Things supporting autonomous cooperating logistics processes, Architecting the Internet of Things, Springer, 2011, 131-158. 